\title{
Expatriates Cultural Adjustment: Empirical Analysis On Individual Cultural Orientation
}

\author{
Wondwossen Kassa Tsegaye, Xi'an Jiaotong University, China \\ Qin Su, Xi'an Jiaotong University, China
}

\begin{abstract}
Previous researches have shown that expatriates 'failure rate has steadily increased in recent years. The failure of expatriates mainly related with the cross-cultural challenges. The purpose of this study was to identify factors which have a paramount implication on expatriates' cultural adjustment. Hierarchical regression and MANCOVA were applied in data analysis. Hofstede's (1980) cultural dimension scores were used to measure culture at national level. The individual cultural orientation was measured using a scale that used Hofstede (1980) dimensions as a framework. Moreover, a recently developed model was adopted to analyze the expatriate adjustment. Cultural adjustment found to be affected more by individual cultural orientation than national culture differences among expatriates ' home and host countries. The alignment of the expatriate cultural orientation with the national culture found to be critical for effective expatriate cultural adjustment. The result indicated that gender difference does not have a significant role in expatriate cultural adjustment. This research would have a conceptual contribution in comprehensively assessing individual cultural orientation with cognitive expatriate adjustment. The study indicated factors that MNCs managers would use for effective selection and assignment of expatriates.
\end{abstract}

Keywords: Expatriates; Cultural Adjustment; Individual Cultural Orientation; Culture Distance

\section{INTRODUCTION}

C n today's world situation, the competition ground for companies has been changing time to time (Hood \& Young, 2000). Hoskisson, Hit, Ireland and Harrison (2008) argued that the proliferation of globalized market created an interconnected marketplace characterized by intense competition across country boarders. The survival of the company depends on its ability to operate in this stiff competition with a globalized market. Companies that confine themselves to the local market would fall behind their multinational competitors (Cullen, 2002). The mere decision to operate globally may not make multinational companies (MNCs) successful, so that it is also essential to face and mitigate cross boarder issues accordingly (Hood \& Young, 2000). As Gerhart and Fang (2005) indicated, cultural differences identified as one of the major sources of challenges in relation with MNCs cross boarder operations. To remain competitive by overcoming these challenges, acquisition of expatriates with global management skills is critical for MNCs (Zahara, Irelan \& Hitt, 2000).

Van der Bank and Rothmann (2006) specified the fact that the number of expatriates assigned in a different cultural setting showed increment time to time. In contrary to the increasing number of expatriates on a foreign country, the failure rate and expatriates premature return also showed an alarming growth. In recent years, the average range of expatriate failure rated as much as $80 \%$, which costed MNCs an enormous fortune (Vögel \& Van Vuuren, 2008). Thus, expatriates' failure has a consequential effect on the MNCs performance. These created compulsions on many researchers, to focus on issues related with expatriates' failures (Jones, Lyu, Runyan, Fairhurst, Kim \& Jolly, 2013). Linder (2015) remarked that many researchers relate expatriates' failures to the cultural adjustment capability. Black and Stephens (1989) defined expatriate adjustment as the extent of harmonious psychological state of expatriates towards the host countries culture. In the expatriate adjustment literature, there were replications and lack of theoretical frame, which made imminent the need for further research (Takeuchi, 2010).

The meta-analysis made by Bhaskar-Shrinivas, Harrison and Luk (2005) identified five common antecedents that had been repetitively applied on previous researches. Many researchers used (Black, Mendenhall \& Oddou, 1991) international adjustment model in analyzing the expatriate adjustment process (Takeuchi, 2010). This might have 
hindered the exploration of new concepts that would contribute to the expatriate adjustment literature. In recent years criticisms were forwarded on the validity of Black et al. (1991) model. Haslberger (2005) argued that the variables in Black et al. (1991) model had not been developed in a systematic theory driven way; in effect, questioned the validity of the three facets of adjustment. Haslberger, Brewster and Hippler (2013) developed a new adjustment model and invited researchers to validate with a cross cultural empirical studies.

Expatriates vary in their ability to adjust themselves in foreign cultures. The determinant factors for these variations were a focus of many researchers. Researchers view regarding the role of culture on expatriate adjustment can be framed in to two major features (Jun \& Gentry, 2005; Kim \& Slocum, 2008). Some researchers concluded that the expatriates' adjustment ability mainly related with the national culture differences between the expatriates' origin and their host country (e.g. Hemmasi \& Downes, 2013; Gerhart \& Fang 2005). In this aspect, the cultural distance (CD) plays a major role in determining the expatriates' adjustment. In contrast, some researchers attributed the expatriate adjustment differences to individuals' ability to cope up new cultural settings than the cultural distance (e.g. Kim \& Slocum, 2008; Jun and Gentry, 2005). An empirical research on related issues would contribute to refine the CD and personal fit paradox. In this regard, a number of researchers attempted to deal the CD and personal fit paradox separately (e.g. Kim \& Slocum, 2008; Hemmasi \& Downes, 2013; Nicholls, Rothstein, \& Bourne, 2002). Jun and Gentry (2005) attempted to study and show the paradox of the two views at the same study. Even though Jun and Gentry (2005) approach were noteworthy, there were some observed limitations on the study. Jun and Gentry (2005) used two different samples to evaluate and compare the two views, which may limit the generalizability of the results. Moreover, their study focused on limited cultural dimension factors. In this regard, comprehensive assessments which consider the interface of $\mathrm{CD}$ and individual cultural orientation appeared to be required.

Pervious researchers have done limited works in dealing culture and MNCs activities in African continent (Senge, 2013). As a matter of fact, in recent years most MNCs expected to increase their operation in Africa (Mmieh \& OwusuFrempong, 2004). This study focused on expatriates in East Africa, specifically Ethiopia. Thus, it would give practical significance for MNCs that may expand in this emerging market continent. Ethiopia located in the Eastern part of Africa, and in recent decade outperformed the world economy by triple and being rated as one of the fastest growing economies in the world (United nation development program, 2016). The double digit economic growth since the year 2003/04 and the huge population accompanied with the wide land coverage attracted many MNCs these days (Deloitte \& Touche Consulting, 2014). Thus, the study will help MNCs to make a knowledgeable decision in the deployment of expatriates abroad.

Generally, this study targeted to enrich and develop the conceptual contribution of previous research endeavors by focusing on areas which need more light to shade on. The study attempted to fill research gaps with a novel research approach. The expatriate adjustment antecedents treated in such a way that consider the comprehensive interface of national culture and individual differences correspondingly; the outcome variables treated with a recent model other than Black et al. (1991) model. These would give a fresh outlook on the expatriate adjustment process; in effect practitioners would gain empirical evidence for expatriate selection and assignment.

\section{LITERATURE REVIEW}

MNCs operate in a diverse economic, legal, and cultural environment. According to Miroshnik (2002) among these major environmental factors, the cultural factor has a special importance for the multinational business. Most of the failures of MNCs revealed to be related with the difficulty to cope up with the external cultural factors (Miroshnik, 2002). Even though various scholars gave different interpretation for the concept of culture, fundamentally culture is the combined software design of the mind, which distinguishes one group or category of people from another (Hofstede, Hofstede \& Minkov, 2010). Hofstede et al. (2010) remarked that people share a collective national character which shapes their perspectives. Morden (1995) stressed that the inclusion of cross cultural conceptions on the management discipline has a paramount importance for effective international management practices (Morden, 1995). Morden (1995) remarked that knowledge about cross cultural issues is a prerequisite for the achievement of MNCs.

Various cross-cultural researches focused on different issues. A research project to be considered as cross cultural, it needed to cover more than one nation or culture group (Berry, 1980). Expatriates are among the subjects dealt in cross 
cultural researches. The ease in placing compatible expatriate influence the MNCs decision to choose the specific Host country (World Bank, 2013). In today`s global economy, MNCs can gain a competitive advantage by effectively assigning employees at international levels (Dowling, Festing \& Engle, 2008). This view goes in line with the resource based theory which explains companies' success with the possession of distinctive resources (Peteraf, 1993). Furthermore, MNCs would also get advantage from returned expatriates' international knowledge and experience (Zhang \& Dodgson, 2007). On the other hand, researchers have different ideas and findings on issues related with cross cultural issues or expatriate issues. To name few of these: cultural dimension, culture role, expatriate adjustment model and individual cultural orientation issues approached by researchers in a number of ways.

\subsection{Cultural Dimensions}

Various models were developed that help the systematic analysis of the national culture. Hofstede (1980) and the global leadership and organizational behavior effectiveness (GLOBE) project (Chhokar, Brodbeck \& House, 2007) were among those studies which attempted to conceptualize and measure national cultures. Hofstede (1980) collected and analyzed data from 62 countries to drive four cultural dimensions: Power distance, collectivism, masculinity and uncertainty avoidance.

Hofstede et al. (2010) defined these nearly exclusive and bipolar dimensions as follows:

a) Power Distance: Power distance signify the distribution of power and the societies' stance towards this distribution. Hofstede et al. (2010) analyzed this with a range that categorize the societies' stance from high to low power distance societies'. Higher power distance societies identified with the existence of power gap between the two members (groups) of the societies', in their formal or informal relationship. There is an observable power gap between the boss and the subordinate, between the elders and the young or between the ruler and the subject. The two members of the society graciously accepts this difference and takes it as a natural phenomenon; and they showed it by respecting individuals or groups in the presumed higher rank. But, the scenario in low power distance societies is different. In such societies, minimum power gap and less difference in the societies' hierarchical relations are observed.

b) Individualism versus Collectivism: denotes the level of focus the society may give for either individualistic or collectivist orientations. Hofstede et al. (2010), denoted that the society may encourage or discourage the two orientations based on the value given for each dimension. In collectivist societies' group safety prevails over individual benefits, in effect individuals expected to sacrifice their interest for the group. In individualistic societies' individuals has a right to take their own path, and encouraged to compete to reveal self-interest.

c) Uncertainty Avoidance: Societies vary in the way how they entertain changes that may come in the future. Some societies have an aversion orientation for the changes that may come in the future. Accordingly, they rely on rules and procedures that prevent unplanned future. According to Hofstede et al. (2010) higher uncertainty avoidance orientation values normal flow of things in the societies' interaction. On the other hand, societies with lower uncertainty avoidance, inclined to accept deviation from normal in their daily interaction. Risk taking and less reliance on rules and regulation could observed in this societies.

d) Masculinity versus Femininity: Masculinity versus femininity refers the extent that the society values agreeableness with that of confrontation. Feminine societies are known by their sympathy towards others, and the emphasis for harmony and relationship. Nonetheless in masculine societies forcefulness valued as a norm. Independence and performance favorably valued in masculine societies.

Long-term dimension was added latter in addition to the aforementioned cultural dimensions. Nonetheless, those East African countries which were covered by Hofstede's (1980) study were not assessed with this dimension. On the other hand, there were criticisms towards the Hofstede (1980) model, among others regarding its external validity and the limitation to focus only on certain aspects of culture (Schwartz, 1994). In this regard, the GLOBE study basically extended Hofstede's (1980) work and assessed culture with nine dimensions. GLOBE differentiate the cultural practices and the cultural values for each dimension. There are also methodological criticisms and commentaries on GLOBE researches (Hofstede et al. 2010). GLOBE study took sub-Saharan Africa as one culture group. Therefore, Hofstede cultural model is preferable than GLOBE model to specifically address East Africa. 


\subsection{Culture Role on Expatriate Adjustment}

Researchers had two perspectives in interpreting culture and its role on the expatriate adjustment: the cultural similarity view and the individual person fit views (Jun \& Gentry, 2005; Kim \& Slocum, 2008).

\subsubsection{Cultural Similarity View}

The cultural similarity view considers national culture as a decisive factor for expatriate adjustment. CD between the expatriates' home and host country considered to be the major determinant antecedent adjustment factor. If the expatriates assigned to a less distant culture, they can adjust faster than a high distant culture. Individual differences were not addressed in this view. All expatriates from the same national culture considered to be similar in their cultural adjustment process (Gerhart and Fang 2005). Hemmasi and Downes (2013) defined CD as those differences which related with the cultural environment of countries. Similarly, Kogut and Singh (1988) defined CD as the degree to which the cultural norms of one country differ from another one. Various scholars attempted to measure CD by basing the quantified cultural dimensions of Hofstede (1980) and GLOBE project. Accordingly, Kogut and Singh (1988) constructed a CD measurement as a composite index based on Hofstede's (1980) national culture scales. They operationalized CD as the sum of the absolute difference between two countries on Hofstede`s (1980) cultural dimensions. But researchers like Beugelsdijk, Maseland, Onrust, Hoorn and Slangen (2015) criticized this approach by claiming that the index lacks validity since it had not considered variations with in a country.

\subsubsection{Person Fit View}

Some researchers rejected the conceptualization of national culture as the major determinant factor on the expatriate adjustment. They argued that, the direct application of country level measurement for individuals would cause ecological fallacy (Yoo, Donthu and Lenartowicz, 2011) Researchers who supported person fit view argued that individual differences played a significant role in expatriate adjustment. They emphasized that there are observable differences among expatriates of the same national culture, which affects their cultural adjustment. The personal fit perspective took national culture as a general structured framework, with in which individual differences prevails (Jun and Gentry, 2005). The individual difference as antecedent of expatriate adjustment treated by various studies in a different way. Among others, the expatriates' personality traits, cultural intelligence and intercultural sensitivity considered as individual antecedents for the expatriate adjustment (e.g. Huff, Song \& Gresch, 2014; Nicholls et al., 2002). Some of these researches presumed individual differences as an isolated variable which has no relation with the national culture. But Takeuchi (2010) suggested that the impact of host country national domain on the expatriate adjustment need further investigation and research.

\subsection{Expatriate Adjustment Models}

Various scholars attempted to conceptualize the cultural adjustment construct and validate it empirically. Mendenhall and Oddu (1985), proposed a multi-dimensional approach of expatriate adjustment by identifying previous research model gaps which had taken expatriate technical competence as the only factor for adjustment. Mendenhall and Oddu (1985) concluded that the expatriate adjustment process comprises four components: self-oriented, others oriented, perceptual and cultural toughness dimensions. Even though the model developed by Mendenhall and Oddu (1985) indicated the multi dimensionality of the adjustment process, it had some drawbacks. Black (1988) took multidimensional conceptualization of expatriate adjustment, like Mendenhall and Oddu (1985), but with a different approach. Black (1988) conceptualized expatriate adjustment as a multidimensional feature which can be viewed as having three primary dimensions; facet, degree and mode. The facet or domain of adjustment denote the question of what the expatriate has to adjust with; the mode of adjustment signify the question of how the expatriate adjusts to the domains; and the degree of adjustment refers the question of adjustment success. By basing Black's (1988) three dimensional dimensions of adjustment Black, Mendenhall and Oddu (1991) developed a comprehensive model of international adjustment which integrated multiple theoretical perspectives. The model formulated seven antecedent factors which have an impact on the cultural adjustment. The antecedents identified by Black et al. (1991) were anticipatory adjustment factors (individual and organization factors) and within country adjustment factors (organization socialization factors, individual factors, job factors, non-work factors and organization culture factors). 
Haslberger, Brewster and Hippler (2013) approached adjustment as a concept which has three dimensions. And criticized the Black et al. (1991) approach as a simple conceptualization which did not represent the complex adjustment process. According to Haslberger et al. (2013), Black et al. (1991) had failed to indicate exhaustively the dimensions of adjustment, and set as simple adjusted or not adjusted dichotomy. They suggested that each adjustment scenario can be broken down in to three components, rather than as a mere adjusted and not adjusted generalization. Such a break down would assist to analyze the adjustment process in a clear manner, in effect to create a meaningful cause and effect relationship among the variables. Haslberger et al. (2013) rejected Black et al. (1991) approach and attempted to show the unnoticed issues in the adjustment process. In the adjustment process the expatriates cognize and interpret their surroundings to a greater or lesser extent, they feel better or worse about it, and they interact more or less well with their hosts (Haslberger et al., 2013). Haslberger et al. (2013) proposed a model that framed expatriate adjustment with three components: cognitive, affective and behavioral. They segregated the expatriate adjustment process not only on these three phases, but each phase also divided as work related and non-work related cultural adjustments. So, they built a model with six identified dimensions in the adjustment process. Obviously, this model breaks down the adjustment process better than that of Black et al. (1991). A thorough analysis of the adjustment dimension would help to easily know which dimension facilitate or hamper the adjustment process. Haslberger et al. (2013) developed a model which focused on the expatriate adjustment, and left open the antecedents. So that, called researchers to extend their model by applying various antecedents to shade light on the expatriate adjustment issues.

\subsection{Individual Cultural Orientation}

As Yoo, Donthu and Lenartowicz (2011) stressed it, the direct application of national culture to individual citizens would led to a faulty analysis result. To resolve this issue few researchers tried to measure individual cultural orientations by applying the metrics of Hofstede (1980) cultural dimensions, but the results were unacceptable (Spector, Cooper, and Sparks, 2001). In this regard, by overcoming the major weakness of past studies, Yoo et al. (2011) developed a scale of individual cultural orientation. Yoo et al. (2011) measures individual cultural orientation by basing the Hofstede (1980) four dimensions' framework: Power distance, uncertainty avoidance, Collectivism and Masculinity. Thus, it gave a common ground to compare the individual orientation and the national level culture. Besides, the scale showed adequate reliability and validity which made it a favored scale to be applied compared to other similar scales. Donthu and Yoo (1998) studied the effect of consumers' cultural orientation on their service quality expectation by using the scale. But a similar study which relate the individual cultural orientation with the expatriate cultural adjustment were unavailable.

\subsection{Conceptual Frame Work and Hypothesis Development}

Institutional theory conceptualizes that organizations are pressured to conform to the institutionalized beliefs and processes of the society they are embedded with. Among others, organizations are subjected to pressures from cultural spheres of society which spill over to employees (Senge, 2013). Lewis (2005) emphasized that the understanding of the culture enables us to predict and adapt to the behavior of entities in specific contexts. In this regard, the various cross cultural studies played a significant role. Hofstede (1980) assessed Ethiopia, Kenya, and Tanzania and Zambia cultural dimensions and established the East Africa's score. The score and the categorization of East African nations based on Hofstede (1980) cultural dimensions matrix indicated in Table 1 (Hofstede et al., 2010). Even though the Hofstede (1980) model helped to objectively compare cultural dimensions, its applicability for recent times were questioned by scholars. In this regard, an overall cross checking comparison was made with the recent world value survey (WVS) project analysis.

Table 1. Hofstede cultural dimensions' scores and categorization of East Africa countries.

\begin{tabular}{|c|c|c|c|}
\hline S.N & Dimension & Score & Catagorization \\
\hline 1 & Power distance & 64 & High \\
\hline 2 & Individualism & 27 & Collectivist \\
\hline 3 & Masculinity & 41 & Feminine \\
\hline 4 & Uncertainty Avoidance & 52 & Weak \\
\hline
\end{tabular}


The world value survey analysis started to assess people's values and beliefs in recent decades. The analysis of world value survey summarized the world culture in to two polarized dimensions: a) Traditional versus secular-rational values dimension and b) survival values versus self-expression values (Inglehart \& Welzel, 2005). These two factors highly correlated with some dimensions of Hofstede`s (1980) cultural assessment model (Hofstede et al., 2010). The traditional and the survival values under world value survey are comparable to the power distance and the collectivism dimensions (Hofstede et al., 2010). World values survey developed a cultural map which segmented the world in to different cultural zones (Inglehart \& Welzel, 2005). East Africa (Zambia and Ethiopia) positioned under the bottom left corner of the map, which signify highest traditional and survival value. As Inglehart and Welzel (2005) indicated higher traditional value shows the society's tendency to accept higher hierarchical power distance; and higher score in survival indicates less individualistic society. The world value survey two parameters and Hofstede`s (1980) scores for individualistic and power distance dimensions has corresponding connotations (Hofstede et al. 2010). When we compare the two studies, the East African region got similar grouping with the two dimensions. Hence, it gives us a logical clue to apply the Hofstede (1980) cultural dimension scores in our study.

Haslberger et al. (2013) expatriate adjustment model were adopted as a frame work. The adopted conceptual frame work indicated in Figure 1, which focused on the cognitive adjustment dimension. The cognitive adjustment is the prerequisite for expatriates' adjustment process which guide their action or behaviors. Brandl and Neyer (2009) explained that the cognitive adjustment starts when an expatriate try to give meaning to the new cultural situations. The interpretation process may be facilitated based on the internal mental orientation of the expatriate. If the expatriate has prior understanding which align with the foreign culture, then the adjustment process would be facilitated. Otherwise the interpretation process would be prolonged with a trial and error base till the expatriate get a clear picture of the new cultural situation (Brandl \& Neyer, 2009). So, it is obvious that if the individual expatriate has an inclination to that cultural situation, the interpretation process would be facilitated. 
Figure 1. Conceptual Frame Work

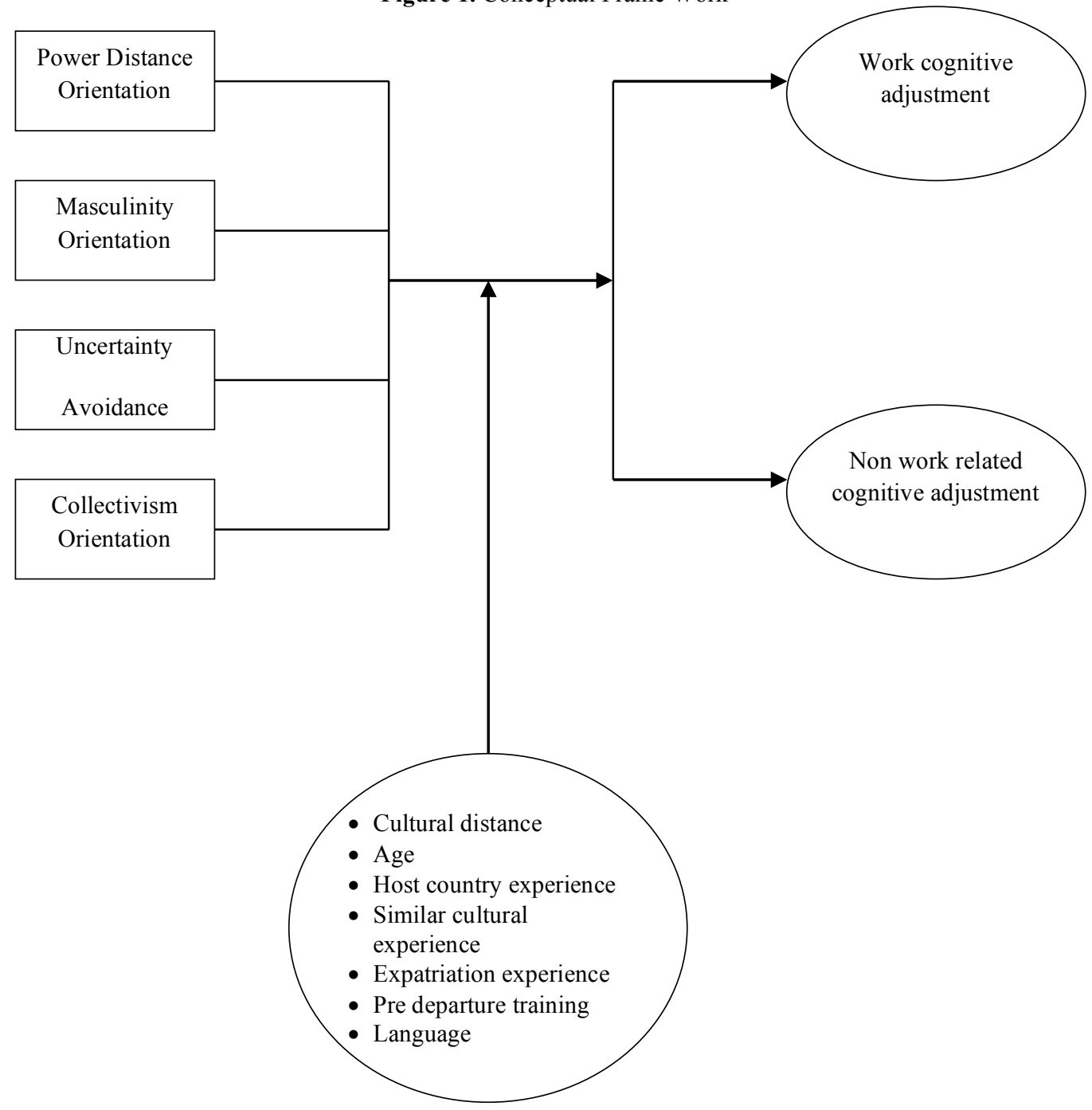

There are contradictory research results regarding the implication of the CD on the expatriate adjustment. Some researchers indicated the inverse relation of $\mathrm{CD}$ with the expatriate adjustment. But, researchers like Hemmasi and Downes (2013) showed scenarios where expatriate adjustment directly related with the CD. On the other hand, there are some researchers who empirically disapproved the implication of CD on the expatriate adjustment. Jun \& Gentry (2005) indicated that cultural similarity does not influence significantly either cognitive uncertainty reduction or satisfaction of expatriates. Ambos and Håkanson (2013) analyzed the emphasis given by researchers for CD and identified misconceptions which need theoretical and empirical refinement. As an endeavor to elucidate the issue, the following hypothesis were developed and tested:

Hypothesis 1: Individual cultural orientation has a superior impact than CD and other demographic factors on: a) work related cognitive adjustment of expatriates b) non-work related cognitive adjustment of expatriates.

Based on Hofstede (2010) cultural dimensions' metrics East African countries categorized under large power distance countries. The score on the dimension implied that East Africans give value for hierarchical relation, they respect their leaders and in general they believe that there is some inequality among peoples, and they accept it as normal. So that, superiors and subordinates considered each other as unequal. In this regard, we hypothesized that expatriates who 
have an individual cultural orientation which aligns to the East African region would easily adjust the cultural environment more easily than others.

Hypothesis 2: Expatriates with high power distance orientation would easily cognitively adjust in the: a) work related environment and b) non-work related environment.

Hofstede (1980) also categorized countries based on their score as individualistic and collectivist (Hofstede et al., 2010). In this respect, East African nations categorized with a collectivist national culture. As per Hofstede et al. (2010) analysis, East African countries encourage interdependence among individuals. In this region, employees are considered as member of in-groups who adhere to the group objectives, and managers expected to be group managers. The employer-employee relationship is expected to be family like. Communication methods under social gatherings and social networks are more effective than internet based electronic medias (Hofstede et al., 2010). Competition, independence and self-orientation are discouraged in these societies. In this regard, expatriates with collectivist orientation would adjust themselves more easily than those with individualistic orientation.

Hypothesis 3: Expatriates with collectivist orientation would easily cognitively adjusting themselves in the: a) work related environment b) non-work related environment.

Based on the masculinity-femininity dimension, Hofstede (1980) categorized countries as masculine and feminine. East African countries categorized under feminine society. In a feminine society, relationship and quality of life are more important than recognition and advancement in a career (Hofstede et al., 2010). So that, assertiveness and behaviors associated with excelling are less accepted in East African regions. In work places conflicts are preferred to be solved with compromise and negotiation. If expatriates have a masculine individual orientation, they would have hard time in adopting the East African culture.

Hypothesis 4: Expatriates with masculine individual cultural orientation would not easily cognitively adjust in the: a) work related environment and b) non-work related environment.

Hofstede et al. (2010) categorized 76 nations based on their uncertainty avoidance dimension score. East African nations labeled under groups of countries with weak uncertainty avoidance. In countries with weak uncertainty avoidance, difference in idea is tolerable. Being different is acceptable in these nations, in contrary to strong uncertainty countries. Countries with strong uncertainty avoidance category, difference considered as something to avoid and dangerous. In this case, expatriates who perceive difference as something to be discouraged may face problem in adopting the East Africa culture.

Hypothesis 5: Expatriates with feminine individual cultural orientation would cognitively adjust more easily in the: a) work related environment and b) non-work related environment.

Gender response towards the cultural values assessed by Hofstede et al. (2010), so as to evaluate the variation towards the cultural dimensions among the respondent employees. Likewise, Caligiuri and Tung (1999) indicated expatriates may show adjustment difference based on their cultural adjustment. To assess the effect of gender on the expatriate adjustment a Hypothesis developed as follows:

Hypothesis 6: Expatriates adjustment would vary based on the expatriates' gender.

\section{RESEARCH METHODOLOGY}

\subsection{Sample Size Determination}

Hofstede et al. (2010) took data from four East African countries (Ethiopia, Kenya, Tanzania and Zambia) to assess the East African cultural dimensions, and rated these countries with similar scores. Following recommendations for sample equivalence in cross-national research (Tsui et al., 2007), the data was taken from one country: Ethiopia. As Bhattacherjee (2012) recommended a realistic approach was followed to develop a representative sampling frame. Fields that expatriates mostly involved in Ethiopia were identified (Ethiopian ministry of labor and social affairs, 
2012). As Connell (2001) indicated firm size has an implication on the employee and the organization culture contexts, hence 23 large MNCs who have more than 100 employees (both home country and expatriates) were identified. This also helped to get a reasonable number of employees that interact with the expatriates, so as to commonly assess the work related cognitive adjustment. The companies were categorized in to four major non overlapping sectors: power construction, manufacturing, service and other sectors. A sampling frame was developed for 263 expatriates working in these companies. The minimum sample size of respondents determined with $5 \%$ error margin and $95 \%$ confidence level (Kothari, 2004). By basing the weighted average ratios for each sector, a total of 200 questioners were distributed randomly for employees identified by excel RAND function.

\subsection{Data Collection}

Survey methodology was used to collect primary data from a random sample of participants. Mackenzie (2003) procedural remedies were applied (keeping respondents anonymity and separation of the independent and dependent variables measurement time) so as to minimize the common method variance. From the distributed questioners 170 were collected. Among these a total of 11 questioners were dropped. 7 questioners were dropped due to missing data and 3 questioners were dropped since the respondents were from similar cultural group country. And 1 respondent discovered to be an Ethiopian by birth and turned his nationality. The collected data adequacy for analysis was examined. For a reliable regression result Stevens (2009) recommended 15 subjects per predictor and Tabachnick and Fidell (2013) developed a formula to use: $\mathrm{N} \geq 104+\mathrm{m}$ (Where $\mathrm{m}=$ number of independent variables). Thus, the sample size fulfilled these requirements.

\subsection{Measures}

$\mathrm{CD}$, age of the expatriate, total expatriation experience, experience in similar culture, host country experience, language and pre departure training was taken as covariates (Berry, 1990; Huff, Song \& Gresch, 2013; Takeuchi, Tesluk, Yun \& Lepak, 2005). Most of the expatriates did not take formal prior training in relation to the East African culture $(90.1 \%)$ and no local language proficiency indicated by the respondents, so these factors were not added in the covariate analysis. To compute CD as a covariate, a formula developed by Kogut and Singh (1988) were applied as indicated in equation 1.

$$
C D_{J U=\sum_{i=1}^{4}\left\{\left(I_{i j}-I_{i u}\right)^{2} / V_{i}\right\} / 4}
$$

where

CD stands for cultural distance, $\mathrm{I}_{\mathrm{ij}}$ is index for the $\mathrm{i}^{\text {th }}$ cultural dimension for the $\mathrm{j}^{\text {th }}$ country, $\mathrm{I}_{\mathrm{iu}}$ is index for the $\mathrm{i}^{\text {th }}$ cultural dimension for the East African countries, $\mathrm{V}_{\mathrm{i}}$ is variance for the $\mathrm{i}^{\text {th }}$ cultural dimension. The $\mathrm{CD}$ were assessed using Hofstede's et al (2010) clustering. The expatriate home countries cultural dimension scores and computed CD indicated in Table 2.

Table 2. Expatriates home and host countries CD

\begin{tabular}{|c|c|c|c|c|c|c|c|c|c|}
\hline & \multicolumn{9}{|c|}{ Dimensions ${ }^{*}$} \\
\hline & \multicolumn{2}{|c|}{ Power Distance } & \multicolumn{2}{|c|}{ Individualistic } & \multicolumn{2}{|c|}{ Masculinity } & \multicolumn{2}{|c|}{$\begin{array}{l}\text { Uncertainty } \\
\text { Avoidance }\end{array}$} & \multirow[t]{2}{*}{$\mathrm{CD}^{* *}$} \\
\hline & Score & Category & Score & Category & Score & Category & Score & Category & \\
\hline China & 80 & Large & 20 & Collectivist & 66 & Masculine & 40 & Weak & 2.38 \\
\hline Italy & 50 & Small & 76 & Individualistic & 70 & Masculine & 75 & Strong & 3.11 \\
\hline Turkey & 66 & Large & 37 & Collectivist & 45 & Feminine & 85 & Strong & 0.82 \\
\hline India & 77 & Large & 48 & Collectivist & 56 & Masculine & 40 & Weak & 0.65 \\
\hline Nigeria & 77 & Large & 20 & Collectivist & 46 & Feminine & 54 & Weak & 0.56 \\
\hline
\end{tabular}

To measure the independent and dependent variables, questioners were adopted from previous researches. All the constructs were measured with a seven point Likert scale anchored by 1 (Completely disagree) and 7 (completely 
agree). Individual cultural orientation was measured using Yoo et al. (2010) scale. The work related cognitive adjustment was measured using Malo, Tremblay and Brunet (2015) adopted scale. The non-work related adjustment measured using the adopted scale of Haslberger (2005). Coefficient alpha applied to identify the internal consistency and reliability of the construct. Tabachnick and Fidell (2013), recommended that selection of the possible covariates need to base on the significant relation with the dependent variable, and the correlation among the covariates must not be large. In this regard, covariates which significantly correlated with the dependent variable and have low correlation among themselves were selected so as to reduce the error variance (Tabachnick \& Fidell, 2013). The total number of covariates used were checked based on the Huitema`s (1980) covariates number determination formula as indicated in equation 2 .

$$
\frac{C+(J-1)}{N}<.10
$$

where

$\mathrm{C}$ stands for the number of covariates, $\mathrm{J}$ stands for the number of groups, and $\mathrm{N}$ stands for the total sample size.

\section{RESULTS}

The average age of the respondents was $36.57(\mathrm{SD}=8.44)$, which range from 24 years up to 59 years. The respondents' average years of experience in the host culture were $1.62(\mathrm{SD}=0.613)$, the average years of experience in similar culture were $1.58(\mathrm{SD}=1.75)$ and the average total expatriation experience were $3.08(\mathrm{SD}=2.99)$. Among the 159 respondents $43.4 \%$ of them were Chinese expatriates, who filled the Chinese translated questioners. And expatriates from Turkish (21.4\%) Italy (14.5\%) Nigeria (6.3\%) and Indian (14.5\%) responded for the questioner. Male respondents totaled $57 \%$ and females $43 \%$. The analysis of the data was made in three parts: Preliminary analysis, hierarchical regression analysis and MANCOVA analysis.

\subsection{Preliminary Analysis Results}

The preliminary analysis was made to assess the fulfilment of those assumptions which required to run the parametric statistical analysis. A Cronbach's alpha coefficient of .80 regarded as a desirable reliability coefficient (Bryman and Bell, 2003).The result showed that $\alpha=.82$ for the 26 items independent variables measure. Each of the 12 items dependent variables measures scored $\alpha=.98$ and $\alpha=.97$ respectively. On the other hand, Kolmogorov-Smirnov univariate normality test was done on both dependent variables for male and female respondents. The data distribution on male respondents for the two dependent variables $(\mathrm{D}(90)=0.097, \mathrm{P}<0.05$, and $\mathrm{D}(90)=0.081, \mathrm{P}<0.05)$ and the data distribution on female respondents $(\mathrm{D}[69]=0.097, \mathrm{P}<0.05$ and $\mathrm{D}[90]=0.070, \mathrm{P}<0.05$.) indicated the significant normal distribution of the data. The P-P plots of regression standardized residual also supported the normality assumption. Furthermore, based on the criterion specified by Tabachnick and Fidell (2013), the correlations between each of the variables have been assessed for multicollinearity and singularity problems. The correlation result with $r \leq 7$ indicated the problem of multicollinearity. In this regard, it was found that there was a significant relationship between the total expatriation experience and the similar culture experience covariate variables $(r=.74, p$ [two-tailed] $<.01)$. And it was identified that the preliminary analysis indicated that there is no significant linear correlation $(\mathrm{r}=.08, \mathrm{p}$ [two-tailed] < .01) between the host country experience and the dependent variable. This might be related with the respondents similar host country experience $(\mathrm{SD}=.61)$. To robust the statistical analysis based on the recommendations of Stevens (2009), the host country experience and total expatriation experience covariates eliminated from the analysis.

After the multicollinearity assumption resolved, correlation analysis computed. The results found to be free from multicollinearity problem $(\mathrm{r}<0.7)$. The variance inflation factor $(\mathrm{VIF})$ and the tolerance statistics values also supports the absence of multicollinearity problem. Assumptions related with homoscedasticity and outliers were tested and no major violation were observed. Besides, those assumptions to conduct MANCOVA were also checked. Among others, multivariate normality and outlier issues were checked by the maximum mahalanobis distance and the maximum cook`s distance. And the results indicated that no major violation of assumptions were observed. The box`s test also 
assure the homogeneity of variance-covariance matrices. Hence, based on the preliminary analysis results parametric statistics can be done.

\subsection{Hierarchical Regression}

For hypothesis testing, the individual cultural orientation dimensions were hierarchically regressed on each of the dependent variables. The covariates entered in the first step of the hierarchical regression and the results indicated in Table 3 and Table 4 for each of the two dependent variables $\left(\mathrm{r}^{2}=.23\right.$ and $\left.\mathrm{r}^{2}=.08, \mathrm{p}<.05\right)$. The introduction of the individual cultural orientation variables in step 2 explained a considerable variation on the two dependent variables $\left(\Delta \mathrm{r}^{2}=.46\right.$ and $\left..42, \mathrm{p}<.05\right)$. The individual cultural orientation impact on the cognitive adjustments was significant compared to the covariates ( $\mathrm{CD}$ and other demographic variables). Thus, H1a and H1b were supported. Moreover, Table 3 indicated that power distance orientation $(\beta=.28, \mathrm{p}<.05)$, uncertainty avoidance $(\beta=-.25, \mathrm{p}<.05)$, collectivism $(\beta=.34, \mathrm{p}<.05)$ and masculinity $(\beta=-.17, \mathrm{p}<.05)$ variables have a significant impact on the work related cognitive adjustment. The impact of $C D$, age and similar culture experience was not significant $(\beta=-.04, \beta=.16$ and $\beta=-.06$, $\mathrm{P}<.05$ ) on the dependent variable. Thus, based on the analysis result $\mathrm{H} 1 \mathrm{a}, \mathrm{H} 2 \mathrm{a}, \mathrm{H} 3$ a and $\mathrm{H} 4$ a were supported.

Table 4 indicated that power distance orientation $(\beta=.30, \mathrm{p}<.05)$, uncertainty avoidance $(\beta=-.43, \mathrm{p}<.050)$ and masculinity $(\beta=-.16, p<.05)$ have a significant impact on the non-work related cognitive adjustment. Whereas, collectivism $(\beta=.11, \mathrm{p}<.05)$ influence on the non-work related variables were insignificant. Based on this result, H3b were rejected and $\mathrm{H} 1 \mathrm{~b}, \mathrm{H} 2 \mathrm{~b}$, and $\mathrm{H} 4 \mathrm{~b}$ were supported. On the other hand, the MANCOVA analysis for females and males indicated on the extracted multivariate test (Table 5). There is no statistically significant difference between males and females expatriates on their cognitive adjustment ( $\mathrm{F}[2,153]=.76, \mathrm{p}=.47$; Wilks` Lambda=.99; partial eta squared=.01). Thus, H 6 was rejected.

Table 3.Summary of hierarchical regression analysis for variables predicting work related cognitive adjustment.

\begin{tabular}{|c|c|c|c|}
\hline Predictor & $\mathbf{R}^{2}$ & $\Delta \mathbf{R}^{2}$ & $\beta$ \\
\hline Step 1 & $.23^{*}$ & $.23^{*}$ & \\
\hline Cultural distance & & & -.04 \\
\hline Similar culture exp. & & & .16 \\
\hline Age & & & -.06 \\
\hline Step 2 & $.69^{*}$ & $.46^{*}$ & \\
\hline Power Distance & & & $.28^{*}$ \\
\hline Uncertainty Avoidance & & & $-.25^{*}$ \\
\hline Collectivism & & & $.34^{*}$ \\
\hline Masculinity & & & $-.17^{*}$ \\
\hline
\end{tabular}

Note: $*$ $<.05$

Table 4. Summary of hierarchical regression analysis for variables predicting non-work related cognitive adjustment.

\begin{tabular}{|c|c|c|c|}
\hline Predictor & $\mathbf{R}^{2}$ & $\Delta \mathbf{R}^{2}$ & $\beta$ \\
\hline Step 1 & $.08^{*}$ & $.08^{*}$ & \\
\hline Cultural distance & & & -.01 \\
\hline Similar culture exp. & & & -.03 \\
\hline Age & & & -.06 \\
\hline Step 2 & $.50^{*}$ & $.42^{*}$ & \\
\hline Power Distance & & & $.30^{*}$ \\
\hline Uncertainty Avoidance & & & $-.43^{*}$ \\
\hline Collectivism & & & .11 \\
\hline Masculinity & & & $-.16^{*}$ \\
\hline
\end{tabular}

Note: ${ }^{\mathrm{p}}<.05$ 


\begin{tabular}{c|l|c|c|c|c|c|c}
\multicolumn{1}{c}{ Table 5. Mancova test result } \\
\hline \multirow{3}{*}{ Eeffect } & Value & F & Hypothesis df & Error df & Sig. & Partial Eta Squared \\
\hline \multirow{3}{*}{ Gender } & Pillai's Trace & .01 & $.76^{\mathrm{b}}$ & 2.00 & 153 & .47 & .01 \\
\cline { 2 - 8 } & Wilks' Lambda & .99 & $.76^{\mathrm{b}}$ & 2.00 & 153 & .47 & .01 \\
\cline { 2 - 8 } & Hotelling's Trace & .01 & $.76^{\mathrm{b}}$ & 2.00 & 153 & .47 & .01 \\
\cline { 2 - 9 } & Roy's Largest Root & .01 & $.76^{\mathrm{b}}$ & 2.00 & 153 & .47 & .01 \\
\hline
\end{tabular}

a. Design: Intercept $+\mathrm{CD}+$ Similarity + Age + Gender

b. Exact statistic

\section{DISCUSSION}

The statistical results presented in part 5 have their own inference on expatriate adjustment. The $\mathrm{r}^{2}$ values indicated in Table 3 and Table 4 explained 23\% and $8 \%$ explained the changes observed on the dependent variables. Thus, it can be seen that the prediction ability of the covariates was very weak. As it can be seen from the $\Delta \mathrm{r}^{2}$ values on table 3 and table 4, the individual cultural orientation explained $46 \%$ of the change on cognitive work related adjustment and $42 \%$ of the non-work related cognitive adjustment. In both cases the result showed that the individual cultural orientation can predict the expatriate adjustment more than CD and other demographic variables. This result was comparable to previous research findings (Jun \& Gentry, 2005; Kim \& Slocum, 2008). This revealed that even if the expatriates came from the same country, they differ in their adjustment response basically on their individual cultural orientation.

Field (2009) stated that the positive or the negative beta $(\beta)$ values indicate the types of relationship between the predictor and the outcome variables. As indicated in both Table 3 and Table 4 individual power distance orientation had positive beta $(\beta)$ values, whereas masculinity orientation and uncertainty avoidance orientation had negative beta $(\beta)$ values. Accordingly, expatriates with high power distance orientation had a better cognitive adjustment (both work related and non-work related). But expatriates with a high uncertainty avoidance and masculinity orientation faced a challenge to easily adjusting themselves in East Africa. Moreover, expatriates with high collectivist orientation had adjusted cognitively in the work related environment. As indicated in Table 4 collectivism had no significant implication on non-work related cognitive adjustment, which refuted the presupposed hypothesis. There are two possible explanations for this result.

Hofstede's (1980) primary study had been published in 1980, and when we add the data collection and analysis period it counted nearly half a century. So, there might be dynamism and changes in some aspects of the cultural dimensions around the East African region in these periods. As Hofstede et al. (2010) indicated, collectivism cultural orientation of a society related with the national wealth of the country. Individualism prevailed on those countries with higher national growth rate; and collectivism expected to be a dominant societal orientation on less developed nations. Ethiopia registered a fastest economic growth in the past few decade (United Nations development program, 2016). Obviously, the growth in the economy may impacted the way how people lives and the collectivist orientation (Hofstede et al., 2010). The cosmopolitan growth and the booming apartment housing may encourage individualistic living styles of the general public. In effect, there might be some changes on the primarily presupposed collectivist orientations.

Second, Hofstede et al. (2010) recently suggested that when we compare the values of individuals, individualism and collectivism should be treated as two separate dimensions. According to them, individuals may exhibit higher collectivism and higher individualism at the same time or on the other way. This is a more detailed approach that segregate the dimension at societal and individual level. GLOBE project decomposed the collectivism in to two: Institutional collectivism and in-group collectivism (Chhokar et al., 2007). Generally, the result indicated the need to decompose the individual collective measure so as to incorporate advanced research findings.

The absolute value results of beta $(\beta)$ indicated the importance of each independent variable in predicating the dependent variables (Tabachnick and Fidell, 2013). As indicated in Table 3 individual orientation based on the beta $(\beta)$ values can be ranked as collectivism, power distance, uncertainty avoidance and masculinity $(\beta=.34, .28,-.25$ and -.17). Hence, the expatriates' collectivism orientation congruence with the host country culture was a critical factor for the expatriates' adjustment. For effective cognitive work adjustment, MNCs need to give priority for the 
congruence of expatriates' orientation and national culture alignment in the indicated importance sequence. In a similar manner, the uncertainty avoidance, power distance and masculinity orientation $(\beta=-.43, .30$ and -.16$)$ can be listed sequentially, based on their importance in predicting non-work related cognitive adjustment. This indicated that expatriates whose uncertainty avoidance orientation aligned with the host national had a high possibility in cognitively adjusting themselves with the non-work environment. Moreover, as indicated in Table 5 Expatriates did not varied in their response towards the cognitive adjustment (both work and non-work). The cognitive adjustment process did not vary due to gender difference. This result is comparable to results of Caligiuri and Tung (1999) who found out no major difference between male and female in their adjustments of international assignments.

\section{CONCLUSION AND RECOMMENDATION}

Identifying factors which have decisive impact on expatriate cultural adjustment was the main objective of this study. The combined effect of $\mathrm{CD}$ and other demographic variables were indicated to be weak on the expatriate adjustment. The study identified the essential role of individual cultural orientation on the expatriates` adjustment. So that, the result strengthen the person fit view of previous researchers. The alignment of individual cultural orientation with the national culture tested to be critical for expatriate adjustment. Among the individual cultural orientation dimensions, the expatriate orientation towards collectivist values identified to be determinant for work related cognitive adjustment. Besides, the expatriate orientation towards uncertainty avoidance identified to be critical for the non work related cognitive adjustment. The expatriate orientation towards collectivism found to have insignificant prediction ability on adjustment, and possible explanations were discussed. Moreover, expatriates do not vary in their cognitive adjustment which related with their gender.

Based on the results it can be concluded that MNCs must not limit themselves on CD and demographic factors to hire and assign expatriates. Rather, they also need to consider the expatriates' individual cultural orientations. MNCs must assess the alignment of the expatriates' cultural orientation with the host country national culture in placing expatriates abroad. The MNCs can expand their pull of assignment to incorporate both genders, since there was no major difference between male and female in cognitive adjustment effectiveness. The study was conducted in a limited geographical area, which may confine the external validity of the findings. Hofstede (1980) established the East African countries culture as similar, so we treated the analysis result for East Africa. But by expanding the sample size and number of countries, it is possible to increase the external validity of the research. In the present study Hofstede (1980) cultural dimensions scores were applied, which may have timeliness issues. Thus, by applying recent models (like GLOBE project) it would be possible to test the empirical validity of the model. Furthermore, longitudinal (rather than cross sectional) studies can be designed so as to strengthen the study results validity.

\section{AUTHOR BIOGRAPHIES}

Wondwossen Kassa Tsegaye is Ph.D. scholar at School of Management, Xi'an Jiaotong University, China. His interests lie in international business management, cross cultural management, leadership development and organizational behavior. He has more than 15 years of experience as management member in public organizations and as an instructor in university colleges. Email: wondwossenk@yahoo.com

Dr. Qin Su is doctoral tutor and department head at School of Management, Xi' an Jiaotong University. Her research interests include quality management, industrial engineering, and enterprise management. She has authored more than 150 peer-reviewed articles in leading international journals. Email: qinsu@mail.xjtu.edu.cn.

\section{REFERENCES}

Ambos, B. \& Håkanson, L. (2013). The concept of distance in international management research. Journal of International Management. 20(2014), 1-7.

Berry, J.W. (1980). Introduction to methodology. In triandis, H.C. and Berry, J.W. (Eds.), Handbook of Cross-Cultural Psychology. Boston: Allyn \& Bacon.

Berry, J.W. (1990). Psychology of acculturation. In J.J. Berman (Ed.), Cross-cultural perspectives: Proceedings of the Nebraska Symposium on Motivation, 37 (pp. 201-234).

Beugelsdijk, S., Maseland., Onrust, M., Hoorn, A.V. \& Slangen, A. (2015). Cultural distance in international business and management: from mean-based measures. The International Journal of Human Resource Management, 26(2), 165- 
191.Retrived from DOI: 10.1080/09585192.2014.922355.

Bhaskar-Shrinivas, P., Harrison, D.A., M.A., \& Luk, D.M. (2005). Input based and time based models of international adjustment: Meta-analytic evidence and theoretical extensions. Academy of Management Journal, 48,257-281.

Bhattacherjee, A. (2012). Social science research: Principles, methods and practices. Florida: Author.

Black, J.S. (1988). Work role transitions: a study of American managers in Japan. Journal of International Business Studies, 19(2), 277-94.

Black, J.S., Mendenhall, M. \& Oddou, G. (1991). Toward a comprehensive model of international adjustment: an integration of multiple theoretical perspectives. Academy of Management Review, 16(2), 291-317.

Black, J. S. \& Stephens, G.K. (1989). The influence of the spouse on American expatriate adjustment and intent to stay in Pacific Rim overseas assignments. Journal of Management, 15, 529-544.

Brandl, J. \& Neyer A.K. (2009). Applying cognitive adjustment theory to cross cultural training for global virtual teams. Human resource management, 48(3), 341-353.

Bryman, A. \& Bell, E. (2003). Business research methods. New York: Oxford University.

Caligiuri, P.M., Tung, R.L. (1999). Comparing the success of male and female expatriates from a US-based multinational company. The International Journal of Human Resource Management, 10 (5), 763-782. Retrieved from doi: $10.1080 / 095851999340143$.

Chhokar, J.S., Brodbeck, F.C. \& House, R.J. (Eds.). (2007). Culture and leadership across the world: The GLOBE Book of InDepth studies of 25 Societies. New Jersey: Lawrence Erlbaum.

Connell, J. (2001). Influence of firm size on organizational culture and employee morale. Journal of Management Research. l(4)-220.

Cullen, J.B. (2002). Multinational Management: A strategic Approach. Cincinnati: South-Western College.

Deloitte \& Touche Consulting. (2014). Ethiopia a growth miracle. Retrieved from https://WWW2.deloitte.com/za/en/pages/strategy/articles/ethiopia-growth-miracle.html.

Donthu, N. \& Yoo, B. (1988). Cultural influences on service quality expectations. Journal of Service Research, 1(2), 178-186. DOI: $10.1177 / 109467059800100207$.

Dowling, P.J., Festing, M. \& Engle, A.D. (2008). International Human Resource Management. Melbourne: Thomson.

Federal democratic republic of Ethiopia, Ministry of labor and social affairs. (2012). The study of expatriate work permit service in Ethiopia. Retrieved from http://www.molsa.gov.et/English/EPro/documents/MOLSA/expatriateemploymentservicestudyreport_opt.Pdf.

Field A. (2009). Discovering statistics using SPSS. London: Sage.

Gerhart, B., \& Fang, M. (2005). National culture and Human Resource Management: Assumptions and evidence. The International Journal of Human Resource Management, 16, 971-986.

Haslberger, A. (2005). Facet and dimensions of cross-cultural adaption: refining the tools. Personnel Review, 34(1), 85-109.

Haslberger, A., Brewster, C. \& Hippler, T. (2013). The dimensions of expatriate adjustment. Human Resource Management, 52(3), 333-351. Retrieved from doi:10.1002/hrm.21531.

Hemmasi, M. \& Downes, M. (2013). Cultural distance and expatriate adjustment revisited. Journal of global mobility: The Home of Expatriate Management Research, 1(1), 72-91.

Hofstede, G. (1980). Culture's consequences: International differences in work-related values. Beverly Hills: Sage.

Hofstede, G., Hofstede, M., M. \& Minkov, M. (2010). Cultures and organization: Software of the mind, intercultural cooperation and it importance for survival. New York: McGraw Hill.

Hood, N. \& Young, S. (Eds.). (2000). The Globalization of multinational enterprise activity and economic development. London: Macmillan.

Hoskisson, R.E., Hitt, M.A., Ireland R.D. \& Harrison J.S. (2008). Competing for Advantage. China: China machine.

Huff, K.C., Song, P., Gresch, E.B. (2013). Cultural intelligence, personality, and cross-cultural adjustment: A study of expatriates in Japan. International journal of Intercultural Relations, 38 (2014), 151-157.

Huitema, B. (1980). The analysis of covariance and alternatives. New York: Wiley.

Inglehart, R. \&Welzel, C. (2005). Modernization, cultural change and democracy. Cambridge: Cambridge University.

Jones, R. P., Lyu, J., Runyan, R., Fairhurst, A., Kim, Y. k. \& Jolly, L. (2013). Cross cultural consensus: development of the universal leadership model. International Journal of Retail and Distribution Management, 42(4), 240 - 266.

Jun, S. \& Gentry, J.W. (2005). An exploratory investigation of the relative importance of cultural similarity and personal fit in the selection and performance of expatriates. Journal of world business, 40, 1-8. Retrieved from doi:10.1016/j.jwb.2004.10.001

Kim, K. \& Slocum, J. (2008). Individual differences and expatriate assignment effectiveness: the case of U.S. based Korean expatriates. Journal of World Business, 43(1), 109 -126. DOI: 10.1016/j.jwb.2007.10.005.

Kogut, B., \& Singh, H. (1988). The Effect of National Culture on the Choice of Entry Mode. Journal of International Business Studies, 19, 411-432.

Kothari, C.R. (2004). Research Methodology: Methods and techniques. New Delhi: New age.

Lewis, R. (2005). When cultures collide: Leading across cultures. Boston: Nicholas brealey.

Linder, C. (2015). Expatriates`willingness to adjust their symbolic leadership abroad. An analysis of how culture affects expatriates use of symbolic interaction. Journal of Global Mobility, 3(3), 244-272. 
Mackenzie, S., B. (2003). Common method biases in behavioral research: a critical review of the literature. Journal of Applied Psychology, 88(5), 879-903.

Malo, M., Tremblay, I., \& Brunet, L. (2015). Cognitive adjustment as an indicator of psychological health at work: Development and validation of a measure. Journal of Vocational Behavior, 92, 33-43.

Mendenhall, M. \& Oddou, G. (1985). The dimensions of expatriate acculturation: a review. Academy of Management Review, 10(1), 39-47.

Miroshnik, V. (2002). Culture and international management: a review. Journal of management development, 21(7), $521-544$.

Mmieh F. \& Owusu-Frempong, N. (2004). State policies and the challenges in attracting foreign direct investment: A review of the Ghana experience. Thunderbird International Business Review, 46(5), 575-99.

Morden, A.R. (1995). International Culture and Management. Management Decision, 33, 2.

Nicholls, C.E., Rothstein, M.G. \& Bourne, A. (2002). Predicting expatriate work attitudes: The impact of cognitive closure and adjustment competency. International Journal of Cross Cultural Management,2(3),297-320.

Peteraf, M.A. (1993). The cornerstones of competitive advantage: a resource-based view. Strategic Management Journal, $14,179-191$.

Schwartz, S.H. (1994). Beyond individualism and collectivism: New cultural dimensions of values. In U. Kim, H. C. Triandis, C. Kagitibasi, S. Choi, \& G. Yoon(Eds.), Individualism and collectivism: Theory, method, and applications. Thousand Oaks: Sage.

Senge, K. (2013). The new institutionalism in organization theory: bringing society and culture back in. The American Sociologist, 44(1), 76-95

Spector, P.E., Cooper, C.L., \& Sparks, K. (2001). An international study of the psychometric properties of Hofstede values survey module 1994: A comparison of individual and country/province level results. Applied Psychology, 50(2), 269 281.

Stevens, J.P. (2009). Applied multivariate statistics for the social sciences. USA: Taylor and Francis.

Tabachnick, B.G. \& Fidell, L.S. (2013). Using multivariate statistics. United States: Pearson.

Takeuchi, R. (2010). A critical review of expatriate adjustment research through a multiple stakeholder view: progress, emerging trends, and prospects. Journal of Management, 36, 1040-1064.

Takeuchi, R., Tesluk. P.E., Yun, S. \& Lepak, D. (2005). An integrative view of international experience. Academy of Management Journal, 48 (1), 85-100.

Tsui, A.S., Nifadkar, S.S. \& Ou, A.Y. (2007). Cross national, cross cultural organizational behavior research: Advances, Gaps, and Recommendations. Journal of Management, 33(3): 462-478.

United Nations development program. (2016). Assessment of development results: Valuation of UNDP contribution to Ethiopia. Retrieved from https://issuu.com/undp-evaluation/docs/adr_ethiopia_en.

Van der Bank, M., \& Rothmann, S. (2006). Correlates of expatriates`cross-cultural adjustment. Management Dynamics, 15(4): 29-40.

Vögel, A. J., \& van Vuuren, J.J. (2008). Preparation, support and training requirements of South African expatriates. South African Journal of Business Management, 39(3): 33-48.

World Bank. (2013). Employing Skilled Expatriates. Retrieved from http://iab.world bank.org//media/FPDKM/IAB/Documents/FDI-Employing-skilled-Expatrriates.pdf.

Yoo, B., Donthu, N. \& Lenartowicz, T. (2011). Measuring Hofstede's five dimensions of cultural values at the individual level: Development and validation of CVSCALE. Journal of international consumer marketing, 23(3-4), 193-210.

Zahara, S.A., Ireland, R.D. \& Hitt, M.A. (2000). International expansion by new venture firms: international diversity, mode of market entry, technological learning, and performance. Academy of Management Journal, 43(5), 925-950.

Zhang, M.Y., \& Dodgson, M. (2007). A roasted duck can still fly away: A case study of technology, nationality, culture and the rapid and early internationalization of the firm. Journal of World Business, 42, 336-349. 


\section{NOTES}

